\title{
ESTIMASI PARAMETER GENETIK PADA UJI KETURUNAN Alstonia scholaris UMUR DUA TAHUN DI GUNUNGKIDUL, YOGYAKARTA
}

Estimates of genetic parameter at two years old of Alstonia scholaris progeny trial in Gunungkidul, Yogyakarta

\author{
Mashudi dan Liliana Baskorowati \\ Balai Besar Penelitian Bioteknologi dan Pemuliaan Tanaman Hutan \\ Jl. Palagan Tentara Pelajar Km. 15, Purwobinangun, Pakem, Sleman, Yogyakarta, Indonesia \\ e-mail:masshudy@yahoo.com
}

Tanggal diterima : 15 Januari 2015, Tanggal direvisi : 29 Januari 2015, Disetujui terbit : 25 Maret 2015

\begin{abstract}
Estimates of genetic parameter were observed at two years old of Alstonia scholaris progeny trial in Gunungkidul, Yogyakarta. The experimental design of the trial was laid out in Randomized Complete Block Design consisting of 48 families, 5 replications, 4 tree-plot and spacing of $4 \times 2$ meters. This study is aimed to observe the growth variation (height and stem diameter) and the estimates of heritability and genetic correlation among the two growth traits. The results of study showed that the tested families were significantly different for height and stem diameter. The estimate of individual heritability was high at around 0.53 and 0.44 for height and stem diameter, respectively. While the corresponding of family heritability was at around 0.67 and 0.63 for height and stem diameter, respectively. Positive and strong genetic correlation were found between height and stem diameter of this species at two years of age $(\mathrm{rg}=0.94)$.
\end{abstract}

Keywords: Alstonia scholaris, genetic parameter, heritability, genetic correlation, progeny trial

\begin{abstract}
ABSTRAK
Estimasi parameter genetik dilakukan pada plot uji keturunan pulai gading (Alstonia scholaris) umur dua tahun di Gunungkidul, Yogyakarta. Rancangan percobaan yang digunakan adalah rancangan acak lengkap berblok, yang terdiri dari 48 famili, 5 blok, 4 pohon per plot dengan jarak tanam $4 \times 2 \mathrm{~m}$. Studi ini dilakukan untuk mengetahui keragaman pertumbuhan, yaitu tinggi dan diameter batang dan menghitung estimasi nilai heritabilitas dan korelasi genetik antara kedua sifat tersebut. Hasil analisis varians menunjukkan bahwa efek famili berpengaruh sangat nyata terhadap pertumbuhan tinggi dan diameter batang. Estimasi nilai heritabilitas individu termasuk dalam kategori tinggi yaitu 0,53 untuk sifat tinggi dan 0,44 untuk sifat diameter batang. Demikian juga estimasi nilai heritabilitas famili termasuk dalam kategori tinggi, yaitu 0,67 untuk sifat tinggi dan 0,63 untuk sifat diameter batang. Korelasi genetik antara tinggi dan diameter batang tanaman pulai gading umur dua tahun bernilai positif dan cukup kuat, yaitu sebesar 0,94.
\end{abstract}

Kata kunci: Alstonia scholaris, parameter genetik, heritabilitas, korelasi genetik, uji keturunan

\section{PENDAHULUAN}

Alstonia scholaris (L.) R.Br. yang

lebih dikenal dengan 'pulai gading' merupakan indigenous species yang cepat tumbuh dan multi guna serta mempunyai sebaran hampir di seluruh wilayah
Indonesia (Soerianegara dan Lemmens, 1994). Pulai sangat prospektif dikembangkan untuk pembangunan hutan tanaman sebagai pemasok kebutuhan bahan baku kayu, antara lain untuk industri pembuatan peti, korek api, hak sepatu, barang kerajinan seperti wayang 
golek dan topeng, pensil "slate" dan pulp.

Saat ini sebagian besar kebutuhan kayu pulai disuplai dari hutan rakyat, namun produksinya baru dapat memasok $\pm 50 \%$ dari kapasitas yang dibutuhkan (Mashudi dkk., 2005).

Produktivitas tegakan beberapa hutan tanaman pulai yang ada saat ini relatif masih rendah dengan rata-rata riap untuk sifat tinggi sebesar 1,04 $\mathrm{m} /$ tahun pada tanaman umur 4 tahun (Muslimin dan Lukman, 2007). Rendahnya produktivitas hutan tanaman pulai ini terjadi karena benih yang digunakan dalam penanaman diperoleh dari tegakan yang belum terseleksi dan belum dimuliakan. Oleh karena itu salah satu aspek yang cukup penting untuk ditempuh dalam mendukung peningkatan produktivitas tegakan pulai adalah penyediaan bibit tanaman yang bermutu dan berkualitas melalui pemuliaan tanaman.

Salah satu bentuk kegiatan dalam upaya pemuliaan tanaman pulai adalah melalui pembangunan plot uji keturunan. Melalui pembangunan uji keturunan ini selanjutnya tindakan seleksi bisa dilakukan secara bertahap agar ke depan dapat dihasilkan benih unggul. Seleksi merupakan salah satu langkah penting dalam upaya penyediaan benih unggul. Namun demikian agar seleksi dalam proses uji keturunan dapat dilaksanakan secara tepat, efektif dan efisien, maka diperlukan informasi parameter genetik berdasarkan data dari plot uji keturunan yang ada.

Dalam mendukung upaya pemuliaan tanaman pulai, plot uji keturunan pulai gading telah dibangun di Kawasan Hutan Dengan Tujuan Khusus (KHDTK) Playen, Gunungkidul, Daerah Istimewa Yogyakarta. Pengamatan dan evaluasi plot uji keturunan ini dilaksanakan secara periodik untuk mendapatkan data dan perkembangan informasi parameter genetik secara komprehensif. Dalam penelitian ini disampaikan hasil evaluasi dan pengamatan plot uji keturunan pulai gading pada umur 2 tahun. Adapun tujuan dari penelitian ini adalah untuk mengetahui taksiran nilai parameter genetik yang meliputi nilai heritabilitas dan korelasi genetik antar sifat tanaman pulai gading pada umur 2 tahun di Gunungkidul, Yogyakarta.

\section{BAHAN DAN METODE}

\section{A. Lokasi penelitian}

Penelitian dilaksanakan pada plot uji keturunan pulai gading yang berlokasi di Kawasan Hutan Dengan Tujuan Khusus (KHDTK) Playen, Gunungkidul, Daerah Istimewa Yogyakarta. Secara geografis lokasi penelitian berada pada $7^{\circ} 58^{\prime} 57,25^{\prime \prime}$ LS dan $110^{\circ} 28^{\prime} 45,20^{\prime \prime}$ BT, elevasi \pm 150 m dpl, curah hujan rata-rata 1.984 
$\mathrm{mm} /$ tahun dan jenis tanah Vertisol. Secara administratif pemangkuan hutan lokasi studi berada dalam wilayah Resort Polisi Hutan Kepek, Bagian Daerah Hutan Playen, Dinas Kehutanan dan Perkebunan Daerah Istimewa Yogyakarta. Secara administratif pemerintahan termasuk dalam wilayah Desa Banyusoco, Kecamatan Playen, Kabupaten Gunungkidul, Daerah Istimewa Yogyakarta.

\section{B. Bahan dan rancangan penelitian}

Bahan yang digunakan dalam penelitian ini adalah tanaman uji keturunan pulai gading umur 2 tahun.
Materi genetik yang digunakan untuk membangun uji keturunan berasal dari 5 populasi, yaitu : Lombok-NTB; JayapuraPapua; Solok-Sumatera Barat; Timor, Nusa Tenggara Timur dan Bali (Tabel 1). Uji keturunan dibangun dengan menggunakan rancangan Randomized Complete Block Design (RCBD) dengan 48 famili, 4 pohon per plot, 5 blok dan jarak tanam $4 \times 2 \mathrm{~m}$. Pada umur 8 bulan, blok ke-4 terbakar sehingga banyak tanaman yang mati dan yang masih hidup pertumbuhannya tidak normal. Terkait dengan hal tersebut maka dalam penelitian ini yang dilakukan analisis hanya data pertumbuhan tanaman dari 4 blok saja.

Tabel 1. Letak geografis, ketinggian tempat, curah hujan dan jumlah famili dari 5 provenan A. scholaris yang diuji di plot uji keturunan

\begin{tabular}{|c|c|c|c|c|c|}
\hline No. & Provenan & Letak Geografis & $\begin{array}{c}\text { Ketinggian } \\
\text { tempat } \\
\text { (m dpl) }\end{array}$ & $\begin{array}{c}\text { Curah } \\
\text { Hujan } \\
(\mathrm{mm} / \mathrm{thn})\end{array}$ & $\begin{array}{r}\text { Jumlah } \\
\text { Famili }\end{array}$ \\
\hline 1. & $\begin{array}{l}\text { Lombok, Nusa } \\
\text { Tenggara Barat }\end{array}$ & $\begin{array}{l}116^{\circ} 13^{\prime} 29,78^{\prime \prime}-116^{\circ} 30^{\prime} 00^{\prime \prime} \text { BT dan } \\
8^{\circ} 20^{\prime} 00^{\prime \prime}-8^{\circ} 33^{\prime} 04,40^{\prime \prime} \mathrm{LS}\end{array}$ & $150-300$ & $1500-2000$ & 29 \\
\hline 2. & Jayapura, Papua Barat & $\begin{array}{l}140^{\circ} 31^{\prime} 26,81-140^{\circ} 39^{\prime} 58,80^{\prime \prime} \mathrm{BT} \\
\text { dan } 2^{\circ} 31^{\prime} 18,43^{\prime \prime}-2^{\circ} 35^{\prime} 04,00^{\prime \prime} \mathrm{LS}\end{array}$ & $500-700$ & $1500-4000$ & 5 \\
\hline 3. & Solok, Sumatera Barat & $\begin{array}{l}100^{\circ} 32^{\prime} 03,00^{\prime \prime}-101^{\circ} 41^{\prime} 30,00^{\prime \prime} \mathrm{BT} \\
\text { dan } 0^{\circ} 51^{\prime} 12,93^{\prime \prime}-1^{\circ} 41^{\prime} 29,32^{\prime \prime} \mathrm{LS}\end{array}$ & $400-600$ & $2000-2800$ & 3 \\
\hline 4. & $\begin{array}{l}\text { Timor, Nusa Tenggara } \\
\text { Timur }\end{array}$ & $\begin{array}{l}124^{\circ} 03 ' 15,42^{\prime \prime}-124^{\circ} 30^{\prime} 13,00^{\prime \prime} \mathrm{BT} \\
\text { dan } 9^{\circ} 266^{\prime} 10,10^{\prime \prime}-9^{\circ} 50 ' 51,42 \text { 'LS }\end{array}$ & $100-400$ & $750-1500$ & 4 \\
\hline 5. & Bali & $\begin{array}{l}115^{\circ} 31^{\prime} 53,91^{\prime \prime}-115^{\circ} 54^{\prime} 8,90^{\prime \prime} \text { BT } \\
\text { dan } 8^{\circ} 21^{\prime} 23,67^{\prime},-8^{\circ} 41^{\prime} 37,92^{\prime \prime} \mathrm{LS}\end{array}$ & $200-350$ & $893,4-2702,6$ & 7 \\
\hline
\end{tabular}

\section{Pengumpulan data}

Data diambil dengan cara melakukan pengukuran sifat pertumbuhan tanaman dengan intensitas sampling 100\%. Sifat yang diukur meliputi tinggi pohon dan diameter batang. Tinggi pohon diukur menggunakan galah meter, sedang diameter batang diukur pada ketinggian 1,3 m (dbh) di atas tanah dengan menggunakan kaliper. Mengingat bentuk batang pulai tidak silindris maka pengukuran diameter dilakukan dengan mengambil nilai rata-rata dari pengukuran pada dua sisi yang 
berbeda, yaitu diameter terkecil dan diameter terbesar.

\section{Analisis data}

Analisis varians digunakan untuk mengetahui variasi diantara perlakuan yang diuji. Analisis varians dilakukan dengan menggunakan data individu tanaman dengan model linier sebagai berikut:

$$
\mathrm{Y}_{i j k}=\mu+\mathrm{B}_{i}+\mathrm{F}_{j}+\mathrm{B}^{*} \mathrm{~F}_{i j}+\mathrm{E}_{i j k}
$$

Keterangan :

$\mathrm{Y}_{i j k} \quad$ : pengamatan individu tanaman ke- $k$ pada blok ke-i dan famili ke- $j$

$\mu \quad$ : rerata umum pengamatan

$\mathrm{B}_{i} \quad$ : pengaruh blok ke- $i$

$\mathrm{F}_{j} \quad$ : pengaruh famili ke- $j$

$\mathrm{B}^{*} \mathrm{~F}_{i l}$ : pengaruh interaksi blok ke- $i$ dengan famili ke-j

$\mathrm{E}_{i j k} \quad$ : random error

Heritabilitas individu dan famili ditaksir menggunakan persamaan berikut ini:

$$
\begin{gathered}
h_{i}^{2}=\frac{2,5 \sigma_{f}^{2}}{\sigma_{f}^{2}+\sigma_{f b}^{2}+\sigma_{e}^{2}} \\
h_{f}^{2}=\frac{\sigma_{f}^{2}}{\sigma_{f}^{2}+\sigma_{f b}^{2} / \mathrm{B}+\sigma_{e}^{2} / \mathrm{NB}}
\end{gathered}
$$

Keterangan :

$h^{2}{ }_{i}:$ nilai heritabilitas individu

$h_{f}^{2}:$ nilai heritabilitas famili

$\sigma_{f}^{2}$ : komponen varian famili

$\sigma_{f b}^{2}:$ komponen varian interaksi famili dan blok

$\sigma_{e}^{2}:$ komponen varian error

B : rerata harmonik jumlah blok

$\mathrm{N}$ : rerata harmonik jumlah individu per plot
Pada persamaan heritabilitas individu, komponen varians famili $\left(\sigma_{f}^{2}\right)$ diasumsikan sebesar $1 / 2,5$ varians genetik aditif $\left(\sigma^{2} \mathrm{~A}\right)$, karena bunga pulai bersifat hermaprodit dengan pembungaan serempak, struktur bunganya axiler yang terdiri dari banyak bunga dalam satu spike sehingga kecenderungan kawin sendiri atau kawin kerabat di hutan alam cukup besar.

Taksiran korelasi genetik antar sifat dihitung menggunakan formula berikut (Zobel dan Talbert, 1984) :

Keterangan :

$$
r_{g}=\frac{\sigma_{F(x y)}}{\sqrt{\sigma_{F(x)}^{2} \cdot \sigma_{F(y)}^{2}}}
$$

$r_{g} \quad:$ korelasi genetik

$\sigma_{F(x y)} \quad$ : komponen kovarian famili untuk sifat $\mathrm{x}$ dan $\mathrm{y}$

$\sigma_{F(x)}^{2} \quad$ : komponen varian famili untuk sifat $\mathrm{x}$

$\sigma_{F(y)}^{2} \quad$ : komponen varian famili untuk sifat y

\section{HASIL DAN PEMBAHASAN}

\section{A. Keragaman Genetik}

Hasil pengukuran menunjukkan bahwa tingkat pertumbuhan tinggi dan diameter batang tanaman pulai gading umur 2 tahun di Gunungkidul, Yogyakarta cukup bervariasi. Hasil perhitungan menunjukkan bahwa rata-rata tinggi tanaman sebesar 2,16 $\pm 0,40 \mathrm{~m}$ dan diameter batang sebesar 3,67 $\pm 1,06 \mathrm{~cm}$ dengan persen hidup tanaman sebesar 90,63\%. Selanjutnya untuk mengetahui keragaman genetik terhadap variabel yang 
diamati maka dilakukan analisis varian sebagaimana disajikan pada Tabel 2.

Tabel 2. Hasil analisis varian karakter tinggi dan diameter batang tanaman pada plot uji keturunan pulai gading umur 2 tahun di Gunungkidul, Yogyakarta

\begin{tabular}{lccc}
\hline \multirow{2}{*}{ Sumber Variasi } & derajat & \multicolumn{2}{c}{ Kuadrat Tengah } \\
\cline { 3 - 4 } & bebas & Tinggi & Diameter Batang \\
\hline Blok & 3 & $\left.48,137^{* *}\right)$ & $\left.278,857^{* *}\right)$ \\
Famili & 47 & $\left.1,435^{* *}\right)$ & $\left.8,322^{* *}\right)$ \\
Famili*Blok & 141 & $\left.0,516^{* *}\right)$ & $\left.3,145^{* *}\right)$ \\
Galat & 504 & 0,163 & 1,141 \\
\hline
\end{tabular}

Keterangan : $* *=$ berbeda nyata pada taraf uji $1 \%$

Hasil analisis varian menunjukkan bahwa famili berpengaruh sangat nyata pada tinggi tanaman dan diameter batang. Hal ini mencerminkan bahwa tinggi dan diameter batang memiliki variasi antar famili. Tingginya variasi genetik dari famili-famili penyusun uji keturunan diduga disebabkan karena jarak antar populasi dimana materi genetik dikumpulkan berjauhan. Disamping itu kondisi ketinggian tempat (elevasi) dan curah hujan juga cukup bervariasi serta adanya keragaman genetik di dalam populasi yang tinggi. Menurut Surmaini dkk. (2011), perbedaan elevasi yang cukup tinggi $( \pm 300 \mathrm{~m})$ akan mengganggu aktivitas fisiologi tanaman sehingga akan mempengaruhi pertumbuhan tanaman antar populasi. Adanya variasi antar famili juga terjadi pada jenis pulai darat (Alstonia angustiloba Miq.) umur satu tahun pada plot uji keturunan di Wonogiri (Mashudi dan Adinugraha, 2014). Hasil analisis ini sejalan dengan hasil penelitian yang dilakukan oleh Hartati dkk. (2007), bahwa observasi keragaman genetik pulai dengan menggunakan penanda RAPD menunjukkan angka yang relatif tinggi, yaitu sebesar 0,2465. Secara umum nilai keragaman genetik pada jenis pulai ini menunjukkan angka yang lebih tinggi dibandingkan dengan nilai rata-rata keragaman genetik kelompok jenis kayu tropis sebesar 0,211 dan pada jenis konifer sebesar 0,207 (Hamrick dan Godt, 1989).

Munculnya keragaman genetik yang tinggi pada jenis pulai tersebut bisa disebabkan oleh adanya perkawinan silang (outcrossing), polinasi yang terjadi dengan bantuan serangga, luasnya sebaran, daur hidup yang panjang, kejadian-kejadian selama tahapan suksesi dan belum adanya perlakuan oleh manusia (Zobel dan Talbert, 1984; Lestyaningsih dkk., 2005). Disamping itu populasi yang berukuran besar dengan letak geografis yang dipisahkan oleh bentang alam seperti gunung, sungai, laut, danau atau padang rumput diduga juga bisa menyebabkan keragaman genetik pulai dalam populasi 
lebih besar dari keragaman genetik antar populasinya (Hartati dkk., 2007).

Beberapa studi pada jenis-jenis kayu tropis yang lain juga menunjukkan adanya keragaman genetik yang besar dalam populasi, yaitu ulin (Rimbawanto dkk.,
2006), meranti tembaga (Rimbawanto dan Suharyanto, 2005; Cao dkk., 2006), merbau (Rimbawanto dan Widyatmoko, 2006), dan araukaria (Widyatmoko dkk., 2010).

Tabel 3. Taksiran komponen varian dan proporsi masing-masing komponen varian terhadap total variasi pada plot uji keturunan pulai gading umur 2 tahun di Gunungkidul, Yogyakarta

\begin{tabular}{lcccc}
\hline \multirow{2}{*}{ Sumber Variasi } & \multicolumn{2}{c}{ Tinggi } & \multicolumn{2}{c}{ Diameter Batang } \\
\cline { 2 - 5 } & $\begin{array}{c}\text { Komponen } \\
\text { Varian }\end{array}$ & Persen (\%) & $\begin{array}{c}\text { Komponen } \\
\text { varian }\end{array}$ & Persen (\%) \\
\hline Blok & 0,30 & 47,62 & 1,74 & 45,91 \\
Famili & 0,07 & 11,11 & 0,36 & 9,23 \\
Famili * Blok & 0,10 & 15,87 & 0,56 & 14,78 \\
Galat & 0,16 & 25,40 & 1,14 & 30,08 \\
Total & 0.63 & 100,00 & 3,79 & 100,00 \\
\hline
\end{tabular}

Taksiran komponen varian untuk masing-masing sifat disajikan pada Tabel 3. Pada sifat tinggi tanaman, komponen varian famili memberikan sumbangan sebesar $11,11 \%$ terhadap varian total. Sedangkan pada sifat diameter batang, komponen varian famili menempati proporsi sebesar 9,23\% terhadap varian total. Dari data tersebut dapat dikatakan bahwa faktor genetik untuk sifat tinggi dan diameter batang menempati proporsi sebesar $\pm 10 \%$. Proporsi ini lebih rendah bila dibanding dengan hasil penelitian Susanto (2010) pada jenis ulin (Eusideroxylon zwageri) umur 1 tahun di Bondowoso, Jawa Timur tetapi lebih besar bila dibanding dengan hasil penelitian Muslimin dkk. (2013) pada uji klon jati (Tectona grandis) umur 5,5 tahun di Kemampo, Sumatera Selatan. Fenomena tersebut dapat dipahami karena jenis ulin terdiri dari 4 varietas (Irawan, 2011) dengan keragaman genetik tinggi $(>0,3) \quad$ (Sulistyowati dkk., 2005; Rimbawanto dkk., 2006a; Irawan, 2011; dan Widyatmoko dkk., 2011). Sedangkan untuk jati, karena materi yang digunakan untuk uji berasal dari klon yang terbatas maka keragaman genetiknya cenderung rendah.

Berdasarkan kenyataan tersebut menunjukkan bahwa keragaman genetik pulai $(0,247)$ memberikan sumbangan yang cukup signifikan terhadap nilai komponen varian famili.

\section{B. Parameter genetik}

\section{Heritabilitas}

Heritabilitas merupakan parameter genetik yang sangat penting dalam 
kegiatan pemuliaan tanaman. Heritabilitas merupakan persentase perbandingan atau proporsi varian genetik terhadap total varian fenotipik (Mangoendidjojo, 2007). Estimasi nilai heritabilitas digunakan untuk mengetahui seberapa besar proporsi faktor genetik dari induk diwariskan kepada keturunannya. Nilai heritabilitas yang tinggi mengindikasikan adanya peluang perolehan genetik yang besar pada keturunannya. Estimasi nilai heritabilitas untuk sifat tinggi dan diameter batang pada plot uji keturunan pulai gading umur 2 tahun disajikan pada Tabel 4.

Tabel 4. Estimasi nilai heritabilitas individu, heritabilitas famili dan korelasi genetik untuk sifat tinggi dan diameter batang tanaman pulai gading umur 2 tahun di Gunungkidul, Yogyakarta

\begin{tabular}{cccc}
\hline Parameter & $\begin{array}{c}\text { Heritabilitas individu } \\
\left(\boldsymbol{h}^{2}\right)\end{array}$ & $\begin{array}{c}\text { Heritabilitas famili } \\
\left(\boldsymbol{h}_{\boldsymbol{f}}{ }_{\boldsymbol{~}}\right)\end{array}$ & $\begin{array}{c}\text { Korelasi genetik } \\
(\boldsymbol{r} \boldsymbol{g})\end{array}$ \\
\hline Tinggi & 0,53 & 0,67 & 0,94 \\
Diameter & 0,44 & 0,63 & \\
\hline
\end{tabular}

Nilai heritabilitas individu maupun heritabilitas famili pada tinggi tanaman dan diameter batang termasuk dalam kategori tinggi. Nilai heritabilitas yang tinggi terjadi karena taksiran nilai komponen varian famili proporsinya cukup tinggi terhadap total varian fenotipiknya (Tabel 3). Heritabilitas individu sifat tinggi sebesar 0,53 dan diameter batang sebesar 0,44 memberikan informasi bahwa 53\% adanya variasi sifat tinggi dan 44\% variasi sifat diameter batang individu-individu tanaman penyusun uji keturunan pulai gading dikendalikan oleh faktor genetik. Demikian juga untuk heritabilitas famili, dimana dari hasil perhitungan $67 \%$ adanya variasi sifat tinggi dan $63 \%$ variasi sifat diameter batang famili-famili penyusun uji keturunan pulai gading dipengaruhi oleh faktor genetik. Nilai heritabilitas tersebut jauh lebih tinggi bila dibanding dengan nilai heritabilitas individu untuk sifat tinggi $(0,05)$ dan diameter batang $(0,05)$ serta heritabilitas famili untuk sifat tinggi $(0,11)$ dan diameter batang $(0,11)$ jenis legaran (Alstonia spectabilis) umur 3 tahun di Wanagama, Gunungkidul (Handoyo, 2011). Tingginya nilai heritabilitas pulai gading diduga karena pulai gading memiliki nilai keragaman genetik yang tinggi $(0,2465)$ dengan proporsi keragaman di dalam populasi besar (85\%) (Hartati dkk., 2007). Disamping itu materi genetik yang digunakan untuk membangun uji keturunan diambil dari populasi-populasi yang jaraknya berjauhan (Tabel 1) sehingga nilai varian genetik dari individu-individu penyusun uji keturunan tersebut tinggi. 
Tingginya nilai heritabilitas tinggi tanaman dan diameter batang tanaman pulai gading menunjukkan bahwa proporsi diwariskannya sifat tersebut sangat besar, sehingga apabila kegiatan pemuliaan dilakukan maka perolehan genetik dari kedua sifat tersebut potensinya sangat tinggi (Dieters dkk., 2002). Nilai heritabilitas juga merupakan petunjuk akan tingkat perolehan genetik (genetic gain) suatu sifat tertentu dan merupakan faktor yang sangat menentukan di dalam keberhasilan program seleksi dan pemuliaan pohon (Zobel dan Talbert, 1984). Dalam kaitannya dengan pekerjaan seleksi, besarnya nilai heritabilitas akan sangat menentukan efektivitas pekerjaan seleksi dan strategi yang tepat dalam pelaksanaan program pemuliaan pohon. Namun demikian perlu dicatat disini bahwa nilai heritabilitas pulai gading tersebut diperoleh dari hasil analisis pada tanaman yang masih muda (umur 2 tahun), sehingga pada umur selanjutnya masih bisa mengalami perubahan.

\section{Korelasi genetik}

Tanaman pulai mempunyai tajuk bertingkat dengan tipologi pertumbuhan tinggi tanaman yang sangat khas, yaitu ada masa tumbuh dan ada masa stagnan (istirahat). Masa stagnan ditandai dengan munculnya percabangan berkarang pada fase pertumbuhannya. Menurut Muslimin dan Lukman (2007) semakin lama masa stagnan maka akan semakin lambat pertumbuhan pulai, namun dengan adanya tindakan pemeliharaan (pemupukan, pembersihan gulma dan pruning) pertumbuhan tunas baru akan semakin cepat terbentuk. Tumbuhnya tunas baru sebagai calon batang yang tumbuh ke arah vertikal menandai berakhirnya masa stagnan. Fenomena pertumbuhan pulai yang khas tersebut diduga akan berpengaruh terhadap korelasi genetik antara tinggi tanaman dengan diameter batang.

Berdasarkan hasil perhitungan, nilai korelasi genetik antara tinggi dan diameter batang tanaman pulai gading memiliki nilai positif dan cukup kuat, yaitu sebesar 0,94 (Tabel 4). Tingginya nilai korelasi genetik ini memberikan indikasi bahwa peningkatan tinggi tanaman hasil pertumbuhan dengan tipologi yang khas akan diikuti oleh peningkatan diameter batang atau sebaliknya dengan korelasi yang cukup kuat. Dalam ilmu pemuliaan pohon, korelasi genetik antar karakter digunakan untuk efisiensi pelaksanaan seleksi. Jika korelasi tersebut konsisten hingga umur tanaman siap diseleksi maka pelaksanaan seleksi bisa efektif dan efisien sebab kegiatan seleksi bisa menggunakan satu sifat saja. 
Pada umumnya korelasi genetik antara karakter tinggi dan diameter batang tanaman kehutanan mempunyai nilai positif tinggi. Pada penelitian ini nilai korelasi genetik lebih tinggi apabila dibandingkan dengan hasil penelitian dari jenis lain, yaitu araukaria umur 1,5 dan 5 tahun masing-masing sebesar 0,8 dan 0,83 (Setiadi, 2010; Setiadi dan Susanto, 2012), sengon umur 1 tahun sebesar 0,85 (Setiadi dkk., 2014), cendana umur 8 bulan sebesar 0,87 (Sumardi dkk., 2014) dan jati umur 5 tahun sebesar 0,84 (Hadiyan, 2009).

\section{KESIMPULAN}

Taksiran nilai heritabilitas individu dan famili sifat tinggi dan diameter batang tanaman pulai gading umur 2 tahun di Gunungkidul termasuk dalam kategori tinggi. Nilai heritabilitas individu sifat tinggi dan diameter batang masing-masing sebesar 0,53 dan 0,44 , sedangkan heritabilitas famili masing-masing sebesar 0,67 dan 0,63 . Tingginya nilai heritabilitas tersebut menunjukkan bahwa proporsi diwariskannya sifat tinggi dan diameter batang sangat besar. Korelasi genetik antara tinggi dan diameter batang tanaman pulai gading umur 2 tahun bernilai positif dan cukup kuat, yaitu sebesar 0,94. Evaluasi secara kontinyu perlu terus dilakukan agar diperoleh hasil yang representatif.

\section{UCAPAN TERIMA KASIH}

Ucapan terima kasih disampaikan kepada semua pihak yang membantu kelancaran penelitian ini, khususnya kepada Surip, S.Hut. dan Maman Sulaeman sebagai teknisi penelitian pulai dan Suroto sebagai tenaga pengawas lapangan yang telah membantu dalam pembangunan plot penelitian dan pengumpulan data.

\section{DAFTAR PUSTAKA}

Cao, C. P., Finkeldey, R., Siregar, I. Z., Siregar, U. J., \& Gailing, O. (2006). Genetic Diversity Within and Among Population of Shorea leprosula Miq. and Shorea parvifolia Dyer (Dipterocarpaceae) in Indonesia Detected by AFLPs. Tree Genetics \& Genomes, 2(4), 225 - 239.

Dieters, M. J., Nikles, D. G., \& Johnson, M. J. (2002). Genetic Improvement and Conservation: A Case Study of Araucaria cunninghamii. Proceedings International Seminar 'Advances in Genetic Improvement of Tropical Tree Species' Yogyakarta, 1 - 3 Oktober 2002 (pp. 89 98). Yogyakarta, Indonesia.

Hadiyan, Y. (2009). Keragaman Pertumbuhan Uji Keturunan Jati (Tectona grandis L.F.) Umur 5 Tahun di Ciamis, Jawa Barat. Jurnal Pemuliaan Tanaman Hutan, 3(2), 95-102.

Hamrick, J. L., \& Godt, M. J. W. (1989). Allozyme diversity in plant species. In A. H. D. Brown, M. T. Clegg, A. L. Kahler, \& B. Weir (Eds.), Plant population genetics, breeding, and genetic resources (pp. 43 63). Massachusetts: Publisher Sunderland, Sinauer Associates Inc.

Handoyo, E. (2011). Evaluasi Uji Keturunan Legaran (Alstonia spectabilis R. Br.) pada Umur 3 Tahun di Petak 18, Hutan Pendidikan Wanagama I, Gunungkidul, Yogyakarta (Skripsi). Fakultas Kehutanan Universitas Gadjah Mada, Yogyakarta.

Hartati, D., Rimbawanto, A., Taryono, Sulistyaningsih, E., \& Widyatmoko, A. Y. P. B. C. (2007). Pendugaan Keragaman 
Genetik di dalam dan Antar Provenan Pulai (Alstonia scholaris(L.) Br.) Menggunakan Penanda RAPD. Jurnal Pemuliaan Tanaman Hutan, 1(2), 89 - 98.

Irawan, B. (2011). Genetic Variation of Eusideroxylon zwageri and its diversity on Variety. Prosiding Lokakarya Nasional Status Konservasi dan Formulasi Strategi Konservasi Jenis-Jenis Pohon yang Terancam Punah (Ulin, Eboni dan Michelia), Bogor 18 - 19 Januari 2011 (pp. 119-131). Pusat Penelitian dan Pengembangan Konservasi dan Rehabilitasi bekerjasama dengan ITTO.

Lestyaningsih, I., Na'iem, M. \& Winarni, W. W. (2005). Variasi Isozim Meranti Merah (Shorea leprosula Miq.) dari Sumatera pada Tegakan Konservasi Ex-situ. Prosiding Seminar Nasional Peningkatan Produktivitas Hutan, Yogyakarta, $26-27$ Mei 2005 (pp. 359 - 371). Kerjasama antara Fakultas Kehutanan UGM dengan International Tropical Timber Organization.

Mangoendidjojo, W. (2007). Dasar-Dasar Pemuliaan Tanaman. Yogyakarta: Penerbit Kanisius.

Mashudi \& Adinugraha, H. A. (2014). Pertumbuhan Tanaman Pulai Darat (Alstonia angustiloba Miq.) dari Empat Populasi pada Umur Satu Tahun di Wonogiri, Jawa Tengah. Jurnal Penelitian Kehutanan Wallacea, 3(1), 75-84.

Mashudi, Adinugraha, H. A., \& Surip (2005). Teknik Perbanyakan Tanaman Pulai Secara Vegetatif. Informasi Teknis Pusat Penelitian dan Pengembangan Hutan Tanaman, 3(2), 58-64.

Muslimin, I., Sofyan, A. \& Islam, S. (2013). Parameter Genetik pada Uji Klon Jati (Tectona grandis L.F.) Umur 5,5 Tahun di Sumatera Selatan. Jurnal Pemuliaan Tanaman Hutan, 7(2), 97-106.

Muslimin, I. \& Lukman, A. H. (2007). Pola Pertumbuhan Pulai Darat (Alstonia angustiloba Miq.) di Kabupaten Musi Rawas, Sumatera Selatan. Prosiding Ekspose Hasil-Hasil Penelitian. Balai Litbang Hutan Tanaman Palembang di Padang 20 September 2006 (pp. 161-166).

Rimbawanto, A., Widyatmoko, A. Y. P. B. C., \& Harkingto. (2006). Keragaman Populasi Eusideroxylon zwageri Kalimantan Timur Berdasarkan Penanda RAPD. Jurnal Penelitian Hutan Tanaman, 3(3), 201-208.
Rimbawanto, A., \& Widyatmoko, A. Y. P. B. C. (2006). Keragaman Genetik Empat Populasi Intsia bijuga Berdasarkan Penanda RAPD dan Implikasinya Bagi Program Konservasi Genetik. Jurnal Penelitian Hutan Tanaman, 3(3), 149-154.

Rimbawanto, A. \& Suharyanto. (2005). Keragaman Genetik Populasi Shorea leprosula Miq. dan Implikasinya untuk Program Konservasi Genetik. Prosiding Seminar Nasional Peningkatan Produktivitas Hutan, Yogyakarta, 26 - 27 Mei 2005 (pp. 373 - 382). Kerjasama antara Fakultas Kehutanan UGM dengan International Tropical Timber Organization.

Setiadi, D., Susanto, M., \& Baskorowati, L. (2014). Ketahanan Serangan Penyakit Karat Tumor pada Uji Keturunan Sengon (Falcataria moluccana) di Bondowoso, Jawa Timur. Jurnal Pemuliaan Tanaman Hutan, 8(1), $1-13$.

Setiadi, D., \& Susanto, M. (2012). Variasi Genetik pada Kombinasi Uji Provenans dan Uji Keturunan Araucaria cunninghamii di Bondowoso, Jawa Timur. Jurnal Pemuliaan Tanaman Hutan, 6(3), 157166.

Setiadi, D. (2010). Keragaman Genetik Uji Provenans dan Uji Keturunan Araucaria cunninghamii Umur 18 Bulan di Bondowoso, Jawa Timur. Jurnal Pemuliaan Tanaman Hutan, 4(1), 1 - 8.

Soerianegara, I., \& Lemmens, R. H. M. J. (1994). Plant Resources of South East Asia 5, Timber Trees: Mayor Commercial Timbers. Bogor: Prosea

Sulistyowati, P., Widyatmoko, A. Y. P. B. C., \& Rimbawanto, A. (2005). Studi Keragaman Genetik 4 Populasi Eusideroxylon zwageri Menggunakan Penanda RAPD. Prosiding Seminar Nasional Peningkatan Produktivitas Hutan, Yogyakarta, 26 - 27 Mei 2005 (pp. 383-395). Kerjasama antara Fakultas Kehutanan UGM dengan International Tropical Timber Organization.

Sumardi, Kurniawan, H., \& Misto. (2014). Evaluasi Uji Keturunan Cendana (Santalum album Linn.) Umur 8 Bulan di Kabupaten Timor Tengah Utara, Nusa Tenggara Timur. Jurnal Pemuliaan Tanaman Hutan, 8(1), $56-68$.

Surmaini, E., Runtunuwu, E., \& Las, I. (2011). Upaya Sektor Pertanian dalam Menghadapi Perubahan Iklim. Jurnal Litbang Pertanian, 30(1), 1 - 7 . 
Susanto, M. (2010). Variasi Genetik Pertumbuhan pada Uji Provenans dan Uji Keturunan Eusideroxylon zwageri di Bondowoso, Jawa Timur. Jurnal Pemuliaan Tanaman Hutan, 4(3), 137-144.

Widyatmoko, A. Y. P. B. C., Lejo, E. S. P., Prasetyaningsih, A., \& Rimbawanto, A. (2010). Keragaman Genetik Populasi Araucaria cunninghamii Menggunakan Penanda RAPD. Jurnal Pemuliaan Tanaman Hutan, 4(2), 63-77.

Zobel, B. J., \& Talbert, J. T. (1984). Applied forest tree improvement (p. 505). New York: John Wiley \& Sons. 
Jurnal Pemuliaan Tanaman Hutan

Vol 9. No. 1, Juli 2015, 1-11 